\title{
BMJ Open Attitudes of Korean smokers towards smoke-free public places: findings from the longitudinal ITC Korea Survey, 2005-2010
}

\author{
Eunja Park, ${ }^{1}$ Sung-il Cho, ${ }^{2}$ Hong Gwan Seo, ${ }^{3}$ Yeol Kim, ${ }^{3}$ Hyun-Suk Jung, ${ }^{4}$ \\ Pete Driezen, ${ }^{5}$ Janine Ouimet, ${ }^{5}$ Anne C K Quah, ${ }^{5}$ Geoffrey T. Fong ${ }^{5,6,7}$
}

To cite: Park E, Cho S, Seo HG, et al. Attitudes of Korean smokers towards smoke-free public places: findings from the longitudinal ITC Korea Survey, 2005-2010. BMJ Open 2019;9:e25298. doi:10.1136/ bmjopen-2018-025298

- Prepublication history for this paper is available online. To view these files, please visit the journal online (http://dx.doi org/10.1136/bmjopen-2018025298).

Received 9 July 2018

Revised 19 March 2019 Accepted 24 June 2019
Check for updates

(C) Author(s) (or their employer(s)) 2019. Re-use permitted under CC BY-NC. No commercial re-use. See rights and permissions. Published by BMJ.

For numbered affiliations see end of article.

Correspondence to Professor Sung-il Cho; persontime@hotmail.com

\section{ABSTRACT}

Objective Prior to December 2012, restaurants in South Korea were required to implement only partial smoking bans. This study documents the changes in Korean smokers' attitudes towards smoking bans between 2005 and 2010 and explores the effects of anti-smoking advertising as a correlate of support for total smoking bans in public places.

Design Longitudinal cohort study of Korean adult smokers.

Setting The data were derived from three waves (2005, 2008 and 2010) of the International Tobacco Control (ITC) Korea Survey.

Participants The ITC Korea Survey respondents were a probability-based, nationally representative sample of Korean smokers aged 19 and older. The current analysis includes 995 smokers who participated in Wave 1 (2005), 1737 smokers who participated in Wave 2 (2008) and 1560 smokers who participated in Wave 3 (2010). Primary and secondary outcome measures Changes in respondents' awareness of secondhand smoke (SHS) harm, attitudes towards smoking bans and personal rules for smoking in private homes and/or vehicles were analysed. Correlates of support for smoking bans in public places were examined using generalised estimating equation regression models.

Results More than $80 \%$ of Korean smokers are aware of the harms of SHS. The proportion of smokers who support smoke-free restaurants or smoke-free bars increased twofold between 2005 and 2010. Smokers who were aware of the dangers of SHS were more likely to support a total smoking ban in workplaces. Noticing anti-smoking advertising or information was not significantly associated with support for a total smoking ban in public places. Conclusions Korean smokers became more supportive of smoking bans in public places between 2005 and 2008. These results show that smokers' attitudes towards smoking bans can change with the implementation of smoke-free policies, even in a country that has a high prevalence of smokers.

\section{INTRODUCTION}

The detrimental health effects of secondhand smoke (SHS) on non-smokers are well established. ${ }^{12}$ The WHO Framework Convention
Strengths and limitations of this study

- A key strength of this study is its longitudinal study design analysis of smokers' attitudes towards smoking bans in public places during the period of the introduction of smoke-free policies (2005-2010).

- The influence of various policy-relevant variables and mediators on smokers' attitudes towards smoking ban was analysed using nationally representative International Tobacco Control Korea survey data.

- As the study population consisted entirely of smokers, the results may not be generalisable to non-smokers or to the general population.

on Tobacco Control (FCTC) includes a provision for protection from exposure to tobacco smoke (Article 8), and smokers and non-smokers alike are increasingly aware of the need for such protection. Recent studies have shown that comprehensive smoke-free policies in public places have positive effects on smokers' health by encouraging smoking cessation. $^{34}$

Although smoking in workplaces and public places is prohibited by law in many countries, ${ }^{5}$ Asian countries, such as the Republic of Korea and China, have been slower to introduce smoke-free policies, compared with Western countries, including Ireland, Australia, Scotland and France ${ }^{6-10}$ Countries with stronger smoke-free policies increasingly implement new smoke-free laws, not only for indoor areas but also for outdoor areas and recreational venues. ${ }^{6-9} 11$ The different social environment in Asian countries in comparison to Western countries, as well as the Asian countries' positioning at an earlier stage along the tobacco epidemic trajectory, may influence the attitudes and behaviours of Asian smokers towards smoke-free policies. To date, Asian smokers' knowledge, attitudes 
and behaviours towards complete smoking bans have not been fully examined. ${ }^{11}$

\section{Smoke-free policies in South Korea}

Since 1995, the Republic of Korea National Health Promotion Act (NHPA) has stipulated partial smoking bans that allow designated smoking areas (DSAs) in large buildings, stores, theatres, hospitals and public transport facilities, among others. Additional policies have since mandated partial smoking bans in places such as schools and public baths (1999); large restaurants, game rooms and government buildings (2003); and factories and local government buildings (2006). Comprehensive smokefree regulation has been implemented in schools, hospitals and childcare facilities since 2003.

In 2010, local governments were given the authority to designate outdoor smoke-free areas and to impose fines for violations. As a result, the local government of Seoul, South Korea's capital city, implemented smoke-free regulations in several outdoor areas, including plazas, bus stops and parks. ${ }^{12} 13$ Other city or provincial governments have also implemented smoke-free laws, ${ }^{14}$ and the NHPA 2012 Amendment banned smoking at expressway service stations and designated cultural heritage areas. In December 2012, Korea introduced a complete smoking ban in the indoor areas of restaurants. The law was initially phased in for large restaurants $\left(>150 \mathrm{~m}^{2}\right.$ area) in December 2012, then for middle-sized restaurants $\left(>100 \mathrm{~m}^{2}\right.$ area) in January 2014 and finally for all restaurants by January $2015 .{ }^{12}$

Factors that have contributed to the delay in introducing smoke-free laws in Korea compared with other high-income countries include the high smoking prevalence among male adults $\left(40.7 \%\right.$ in 2016) ${ }^{15}$ and the pro-smoking social culture. ${ }^{16}$

Smoking bans contribute to a gradual process of 'denormalisation' of smoking over time, in which attitudes of smokers and non-smokers shift from acceptance to regarding smoking as an atypical behaviour. During this shift of cultural norms, smoking becomes increasingly stigmatised. ${ }^{1718}$ As a result of such a cultural environment, smokers may increasingly recognise non-smokers' desires for smoke-free environments and choose to modify their own smoking behaviours. ${ }^{19}$

The current study adds to the literature by examining changes in smokers' attitudes to smoking bans in South Korea, a country with high smoking prevalence compared with other industrialised nations. Because the Korean government ran mass media campaigns advertising the restriction of smoking in public places since 2005, this study specifically examined the effects of anti-smoking advertising on smokers' support for total smoking bans in public places during the study period.

The International Tobacco Control Policy Evaluation (ITC) Project is a series of longitudinal cohort surveys aimed at evaluating the tobacco control policies of the WHO FCTC, which has been conducted across 29 countries. $^{20}{ }^{21}$ The ITC Korea Survey was initiated in 2005 to examine patterns of smoking behaviours and the impact of tobacco control policies in South Korea. ${ }^{22}$

The objectives of this paper were (1) to describe changes in Korean smokers' self-reported awareness of the harms of SHS exposure, attitudes towards total smoking bans and personal rules regarding banning or allowing smoking in private homes or vehicles and (2) to explore the effects of anti-smoking advertising on self-reported support for total smoking bans in public places given that partial, rather than complete, smoking bans were in force between 2005 and 2010.

\section{METHODS \\ Study design and procedures}

Longitudinal data from three waves of the ITC Korea Survey were used to estimate changes in self-reported awareness, attitudes and personal rules from 2005 (Wave 1) to 2010 (Wave 3). The ITC Korea Survey is a nationally representative cohort survey of Korean adult smokers aged $\geq 19$ years. Data were collected using a computer-assisted telephone interviewing method. In short, the ITC Korea Survey assessed smokers' knowledge, attitudes, beliefs, perceptions and behaviours regarding tobacco use and tobacco control policies. ${ }^{20}$

The survey questions were selected from a database of ITC Project questions that had initially been developed through systematic and iterative expert review and revision, and in many cases, tested in different populations. The selected questions were then adapted to the Korean context. The adapted ITC Korea Survey questions and any uniquely new questions were refined via the standard ITC systematic process by the Korea Team and ITC International Team. The survey items were pilot tested in a sample of smokers prior to full implementation. ${ }^{21} 22$

A nationally representative sample of 1002 Korean adults who had smoked cigarettes in the last month and had smoked at least 100 cigarettes in their lifetimes was sampled in Wave 1 (2005) using a probability-based stratified random sampling design. For Waves 2 (2008) and 3 (2010), respondents who had completed the survey in Wave 1 were re-contacted. A replenishment sample of new respondents replaced smokers lost to attrition. The retention rate was $44.01 \%$ in Wave 2 and $56.60 \%$ in Wave $3 .{ }^{23}{ }^{24}$ Details of the survey data collection methodology have been reported elsewhere. ${ }^{423-26}$

In this study, respondents who had ceased smoking at the time of the survey were excluded from the analyses $(\mathrm{n}=7$ at Wave $1, \mathrm{n}=81$ at Wave 2 and $\mathrm{n}=193$ at Wave 3$)$. Therefore, the results are based on 995 smokers who participated in Wave 1, 1737 smokers who participated in Wave 2 and 1560 smokers who participated in Wave 3.

\section{Patient and public involvement}

Data obtained from smokers who participated in ITC Korea Survey pilot study informed the relevance of questions. A summary of the data analyses are presented online. ${ }^{22}$ 


\section{Measures}

The following questions related to participants' awareness of anti-smoking advertising and the harm of SHS as well as their attitudes towards smoking bans in public places and personal rules for smoking in private homes and vehicles were asked.

\section{Awareness of anti-smoking advertising or information}

1. 'Now I would like you to think about advertising or information that addresses the dangers of smoking or encourages quitting. In the last 6 months how often, if at all, have you noticed such advertising or information?' (1=never, 2=rarely, 3=sometimes, 4=often, 5=very often). Smokers who selected sometimes, often or very often were classified as having noticed anti-smoking advertising or information.

\section{Awareness of harms of secondhand smoke exposure}

2. 'Does smoking cause lung cancer in non-smokers from secondhand smoke?' (1=yes, 2=no, 9=do not know). This question was asked in Waves 1 and 2 only.

3. 'Do you agree/disagree with the following statement: cigarette smoke is dangerous to non-smokers' (1=strongly agree, 2=agree, 3=neither agree nor disagree, $4=$ disagree and $5=$ strongly disagree). This variable was classified as a dichotomous variable (strongly disagree, disagree or neither agree nor disagree vs strongly agree or agree) in regression models.

\section{Support for smoking bans in public places}

4. 'For each of the following public places, please tell me if you think smoking should be allowed in all areas, in some areas or not allowed at all.'

a. Workplace: (1=all indoor areas, $2=$ some indoor areas, $3=$ not at all).

b. Indoor areas, 'indoor areas of restaurants/cafes' and 'indoor areas of drinking establishments': (1=all indoor areas, 2=someindoor areas, $3=$ not at all).

c. Outdoor areas, 'outdoor areas of restaurants / cafes', 'outdoor areas of drinking establishments', 'bus stops', 'crowded streets' and 'parks': (1=all outdoor areas, $2=$ some outdoor areas, $3=$ no outdoor areas at all). These questions were asked in Waves 2 and 3 only.

Three categories of attitudes towards workplace smoking bans were created: (1) total smoking ban (ie., smoking should not be allowed at all); (2) partial smoking ban (ie., smoking should be allowed in some indoor areas) (3) and no ban (ie., smoking should be allowed in all indoor areas). The same categories were used to classify the attitudes for smoking bans in indoor areas of restaurants/cafes or drinking establishments. Attitudes for outdoor smoking bans were also defined using these categories: (1) total smoking ban (ie., smoking should not be allowed at all); (2) partial smoking ban (ie., smoking should be allowed in some outdoor areas) (3) and no ban (ie., smoking should be allowed in all outdoor areas).
Personal rules banning smoking in private homes and vehicles

5. 'Which of the following best describes smoking inside your home?' ( $1=$ smoking is allowed anywhere in my home, $2=$ smoking is never allowed anywhere in my home, $3=$ something in between). 'Smoking is never allowed anywhere in my home' was coded as a total home smoking ban.

6. 'When you are in a car or other private vehicle with non-smokers do you...?' ( $1=$ smoke as you normally smoke, $2=$ never smoke, $3=$ something in between). 'Never smoke' was coded as having a smoking restriction in vehicles.

\section{Sociodemographics and smoking-related characteristics}

Sociodemographic variables included age (18-24 years, 25-39, 40-54, 55+), gender (male, female), marital status (married, never married, others (separated, widowed and divorced)), highest level of educational attainment (middle school or lower, high school, college or higher) and household income (low <30 $000000 \mathrm{KRW}$, middle=30 000 000-44 $999000 \mathrm{KRW}$, high $\geq 45000000$ KRW). Cigarette consumption was measured in terms of cigarettes per day $(1-10,11-20,21+)$ by asking the respondents how many cigarettes they smoked daily.

\section{Time-in-sample and survey year}

Since $45 \%$ of respondents recruited in Wave 1 were followed up in subsequent waves, samples from Waves 2 and 3 were composed of respondents who were re-contacted from previous waves as well as newly recruited respondents. To adjust for differences between the newly recruited respondents and cohort respondents who had participated in previous waves, a time-in-sample variable (the number of ITC Korea Survey waves completed by each respondent) was used as a covariate in the regression models. The survey year was also added to the regression models to examine the period effect.

\section{Statistical analysis}

Descriptive statistics were presented for the characteristics of the study population, SHS-related harm awareness, attitudes towards smoking bans and personal rules for smoking in private homes and/or vehicles. Multinomial logistic regression was used to test for changes in awareness of the harm associated with SHS and attitudes towards smoking bans and restrictions between 2005 and 2008 and between 2008 and 2010. Standard errors were adjusted for clustering among individual participants.

We used generalised estimating equation (GEE) regression models with an exchangeable correlation matrix to examine the association between awareness of anti-smoking advertising and attitudes towards total smoking bans in public places across the three waves. GEE models not only provide population-averaged estimates for repeated measures data, but can also be used to test the temporal trend across survey waves. To examine the robustness of the GEE regression model assumptions, we repeated the analysis using an unstructured working 
Table 1 Characteristics of the study population, ITC Korea Survey

\begin{tabular}{|c|c|c|c|}
\hline & $\begin{array}{l}2005(W 1) \\
(n=995)\end{array}$ & $\begin{array}{l}2008 \text { (W2) } \\
(n=1737)\end{array}$ & $\begin{array}{l}2010(W 3) \\
(n=1560)\end{array}$ \\
\hline \multicolumn{4}{|c|}{ Age (years), n (\%) } \\
\hline $18-24$ & $74(7.4)$ & $129(7.4)$ & $81(5.2)$ \\
\hline $25-39$ & $313(31.5)$ & 485 (27.9) & 353 (22.6) \\
\hline $40-54$ & 347 (34.9) & $596(34.3)$ & 503 (32.2) \\
\hline $55+$ & 261 (26.2) & $527(30.4)$ & $623(40.0)$ \\
\hline
\end{tabular}

Gender, n (\%)

\begin{tabular}{|c|c|c|c|}
\hline Male & 954 (95.9) & $1668(96.0)$ & $1484(95.1)$ \\
\hline Female & $41(4.1)$ & $69(4.0)$ & $76(4.9)$ \\
\hline \multicolumn{4}{|l|}{ Marital status, n (\%) } \\
\hline Married & 722 (72.8) & $1234(71.3)$ & $1121(71.9)$ \\
\hline Never married & $200(20.2)$ & 394 (22.8) & 316 (20.3) \\
\hline Others & $70(7.0)$ & $102(5.9)$ & $122(7.8)$ \\
\hline \multicolumn{4}{|l|}{$\begin{array}{l}\text { Educational } \\
\text { attainment, } \mathrm{n}(\%)\end{array}$} \\
\hline $\begin{array}{l}\text { Middle school or } \\
\text { less }\end{array}$ & 209 (21.2) & 319 (18.9) & 324 (21.3) \\
\hline High school & $420(42.7)$ & $773(45.8)$ & $679(44.5)$ \\
\hline College or more & $356(36.1)$ & 595 (35.3) & $522(34.2)$ \\
\hline
\end{tabular}

\begin{tabular}{|c|c|c|c|}
\hline \multicolumn{4}{|c|}{$\begin{array}{l}\text { Household } \\
\text { equivalent income, } \\
\mathrm{n}(\%)\end{array}$} \\
\hline Low & $431(47.3)$ & $696(46.0)$ & $682(51.0$ \\
\hline Middle & 239 (26.2) & $362(23.9)$ & $287(21.4$ \\
\hline High & 242 (26.5) & $456(30.1)$ & $370(27.6$ \\
\hline \multicolumn{4}{|c|}{$\begin{array}{l}\text { Cigarettes per day, } \\
\mathrm{n}(\%)\end{array}$} \\
\hline $1-10$ & $284(28.5)$ & $550(31.7)$ & 535 (34.4 \\
\hline $11-20$ & $547(55.0)$ & 924 (53.2) & $792(51.0$ \\
\hline $21+$ & $164(16.5)$ & $263(15.1)$ & 227 (14.6) \\
\hline \multicolumn{4}{|c|}{$\begin{array}{l}\text { Notice anti-smoking } \\
\text { advertising or } \\
\text { information, } \mathrm{n}(\%)\end{array}$} \\
\hline No & $525(52.8)$ & $552(32.0)$ & $613(39.8$ \\
\hline Yes & $470(47.2)$ & $1173(68.0)$ & $929(60.2$ \\
\hline \multicolumn{4}{|c|}{$\begin{array}{l}\text { Wave of recruitment, } \\
\mathrm{n}(\%)\end{array}$} \\
\hline Wave 1 & 995 (100.0) & $360(20.7)$ & 215 (13.8 \\
\hline Wave 2 & & $1377(79.3)$ & $621(39.8$ \\
\hline Wave 3 & & & $724(46.4$ \\
\hline
\end{tabular}

*Low:<30 000000 won; middle: 30000 000-44 999000 won; high: $\geq 45000000$ won.

correlation. The results of both analyses were similar; therefore, we presented only the results of the models that were estimated using an exchangeable correlation matrix. 'Do not know', 'Refused' and 'Not Applicable' responses were treated as missing, and respondents with missing data on the explanatory or outcome variables were excluded from the GEE regression analysis. Data were weighted so that results represent the population of adult smokers in Korea (except in table 1). Data were analysed using STATA (V.11.0; Stata Corp, College Station, Texas, USA) for Windows. A p-value $<0.05$ was considered statistically significant.

\section{RESULTS}

\section{Sociodemographic and smoking profile}

Respondents aged 25-54 accounted for $66.4 \%$ of the study population in $2005,62.2 \%$ in 2008 and $54.8 \%$ in 2010. The proportion of respondents who were aged $\geq 55$ increased from $26.2 \%$ in 2005 (Wave 1) to $40 \%$ in 2010 (Wave 3) (table 1). Approximately, one-third of respondents were college graduates, and around half smoked 11-20 cigarettes per day. By 2010 (Wave 3), 60\% of smokers reported having noticed anti-smoking advertising or information, compared with 47\% in 2005 (Wave $1)$.

\section{Awareness of harms of SHS exposure}

Table 2 presents the changes over time in awareness of SHS-related harm, support for smoking bans in public places and personal rules for banning/allowing smoking in private places between 2005, 2008 and 2010. In 2005 and $2008,79 \%$ and $85 \%$ of smokers, respectively, knew that passive smoking caused lung cancer in non-smokers. Across all three waves, $>80 \%$ of smokers agreed that SHS was dangerous to non-smokers.

\section{Support for total smoking bans}

Support for total smoking bans in both indoor and outdoor public places increased between 2005 and 2010 (table 2). Support for total smoking bans in the indoor areas of workplaces increased from $17.7 \%$ in 2005 to $34.4 \%$ in 2010 ( $p<0.001$ from 2005 to $2008, p=0.315$ from 2008 to 2010). The proportion of smokers who supported $100 \%$ smoke-free restaurants or smoke-free bars approximately doubled between 2005 and 2008 (restaurant and cafe indoor areas: $15.6 \%$ vs $29.7 \%$, drinking establishment indoor areas: $5.8 \%$ vs $12.0 \%$ ), but the majority of smokers expressed support for partial smoking bans compared with total smoking bans, particularly for drinking establishments. Around 54.6\% supported partial bans compared with $14 \%$ who supported complete bans in the indoor areas of drinking establishments in 2010. Although the proportion of smokers who supported total smoking bans in the outdoor areas of restaurants or drinking establishments increased over time $(p<0.001)$, $<10 \%$ of smokers in any wave supported a total smoking ban. However, the proportions of smokers who supported a total smoking ban at bus stops, on crowded streets or in parks significantly increased from $29.9 \%, 28.0 \%$ and $18.4 \%$, respectively, in 2008 to $44.2 \%, 36.6 \%$ and $29.8 \%$ in $2010(\mathrm{p}<0.001)$.

There was a significant increase in the percentage of smokers who implemented personal smoking bans in private homes $(\mathrm{p}<0.001)$ or vehicles $(\mathrm{p}<0.001)$ between 2005 and 2010. More than half of the smokers reported 
Table 2 Changes in harm awareness regarding SHS and attitudes towards smoking bans and smoking restrictions among smokers between 2005 and 2010

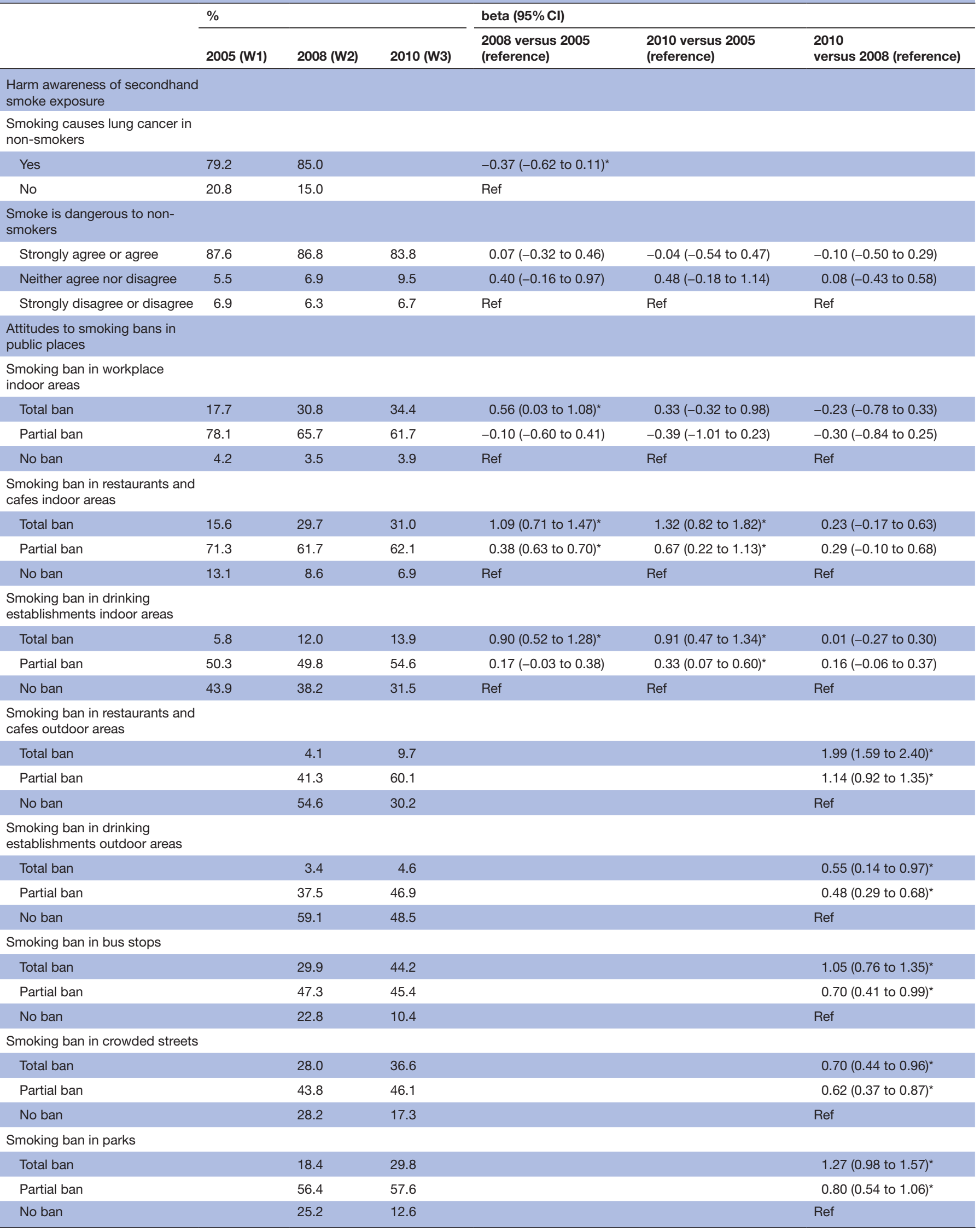


Table 2 Continued

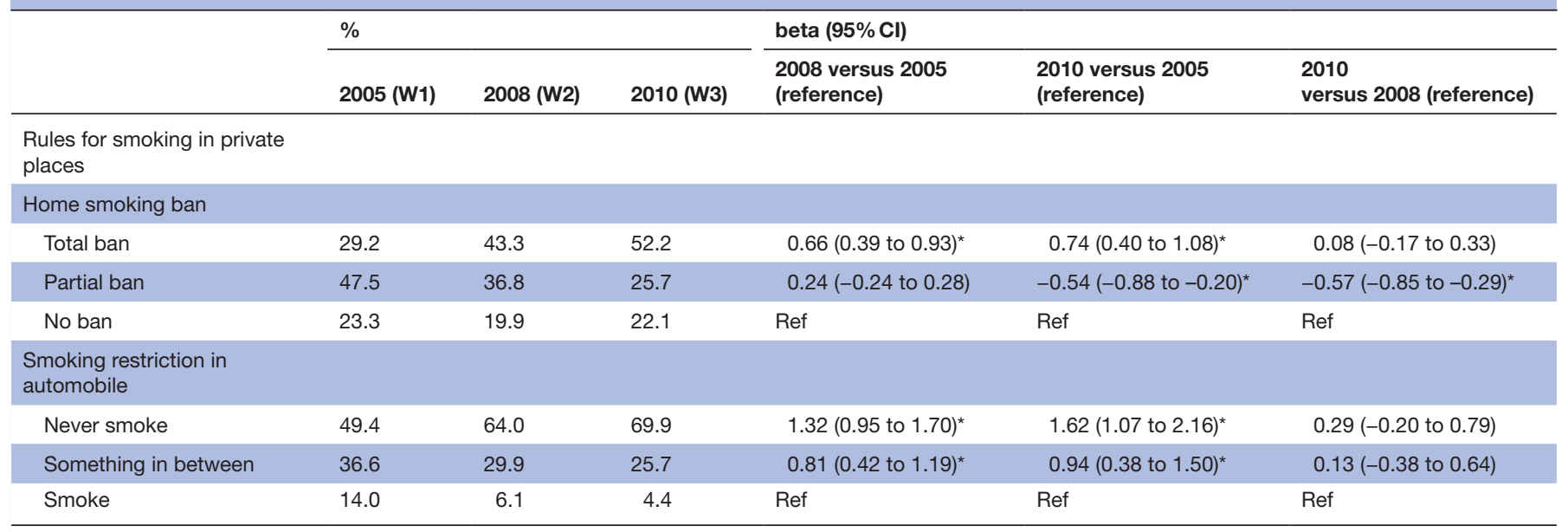

${ }^{*} \mathrm{P}$ value $<0.05$ from multinomial regression adjusted for age, gender, marital status, educational attainment, household equivalent income, cigarette consumption and time-in-sample.

SHS, secondhand smoking.

that smoking was never allowed anywhere in their homes or vehicles in 2010 (home: 52.2\%, vehicle: $69.9 \%$ ) compared with 2005 (home: $29.2 \%$, vehicle: $49.4 \%$ ).

\section{Factors associated with support for total smoking bans}

Tables 3 and 4 show the results of the GEE regression models with regard to awareness of anti-smoking advertising (explanatory variable \#1); awareness of SHS-related harm (explanatory variable \#2); support for total smoking bans in indoor areas (outcome variables) and support for total smoking bans in the outdoor areas of public places (outcome variables) controlling for covariates (ie., sociodemographic characteristics, smoking intensity, personal rules for smoking in homes and/or vehicles, time-insample and survey year).

Smokers who agreed that smoke is 'dangerous to non-smokers' had a 1.55 times greater likelihood of supporting a total smoking ban in workplaces than smokers who did not agree (95\% CI: 1.17 to 2.04, $\mathrm{p}<0.001$, table 3 ). Having personal rules against smoking at home and/or in private vehicles was positively associated with support for total smoking bans in public places. However, awareness of anti-smoking advertising/information was not associated with support for total smoking bans in indoor areas of public places. Older age, male gender, lower educational attainment and lower cigarette consumption were positively related to support for total smoking bans in the indoor areas of public places but not to all of the outcome variables. The likelihood of the respondents supporting total smoking bans in the indoor areas of workplaces, restaurants/cafes and drinking establishments increased significantly between 2005 and 2008, whereas the differences between 2008 and 2010 were not significant (table 3). Support for total smoking bans in the outdoor areas of restaurants/cafes increased significantly between 2008 and 2010 (table 4). There was no significant association between respondents' having noticed anti-smoking advertising/information and their support for total smoking bans in the outdoor areas of public places.

\section{DISCUSSION}

This paper documents the changes in Korean smokers' awareness of the harms associated with SHS exposure, the attitudes towards total smoking bans and personal rules regarding banning or allowing smoking in private homes and vehicles between 2005 and 2010. The majority of Korean smokers were well aware that SHS is dangerous to non-smokers ( $84 \%$ in 2010), and there were notable increases in the proportion of smokers who supported total smoking bans in public places, and who adhered to personal rules against smoking in private homes and/or in private vehicles with non-smoking passengers between 2005 and 2008. This result is noteworthy in that men still show a high rate of smoking prevalence in South Korea. The smoking prevalence of men was not much changed during the study period from $51.6 \%$ in 2005 to $48.3 \%$ in $2010 .{ }^{15}$ Despite the high smoking rate and pro-smoking culture, the proportion of smokers who supported $100 \%$ smoke-free restaurants or smoke-free bars increased greatly between 2005 and 2008 .

Smoking was a socially acceptable behaviour for Korean men in the past, ${ }^{16}$ but the prevalence of smoking among men decreased substantially between 1989 and 2003. ${ }^{27}$ Regulations on smoking in public places have become stronger, and anti-smoking campaigns have become more focused on SHS. For example, the theme of an anti-smoking campaign in 2007-2008-'say no to SHS'suggested that non-smokers should tell smokers not to smoke in their presence.

Our study results did not indicate a significant positive association between noticing anti-smoking advertising/information and support for a total smoking ban in public places (ie., indoor areas of workplaces, and 
Table 3 Odds ratio $(95 \% \mathrm{Cl}$ ) of support for total smoking ban in indoor areas of public places over three waves (in 2005, 2008 and 2010) of the ITC Korea Survey

\begin{tabular}{|c|c|c|c|}
\hline & $\begin{array}{l}\text { Workplace } \\
(n=3475)\end{array}$ & $\begin{array}{l}\text { Restaurants or cafes } \\
(\mathrm{n}=3530)\end{array}$ & $\begin{array}{l}\text { Drinking } \\
\text { establishments } \\
\text { ( } n=3494)\end{array}$ \\
\hline \multicolumn{4}{|l|}{ Notice anti-smoking advertising or information } \\
\hline No & 1.00 & 1.00 & 1.00 \\
\hline Yes & 0.91 (0.76 to 1.09$)$ & $0.94(0.79$ to 1.13$)$ & $1.08(0.85$ to 1.38$)$ \\
\hline \multicolumn{4}{|l|}{ Smoke is dangerous to non-smokers } \\
\hline Do not agree/neither agree nor disagree & 1.00 & 1.00 & 1.00 \\
\hline Strongly agree or agree & $1.55(1.17 \text { to } 2.04)^{*}$ & 1.25 (0.95 to 1.66$)$ & 1.44 (0.96 to 2.14$)$ \\
\hline \multicolumn{4}{|l|}{ Age (years) } \\
\hline $18-24$ & 1.00 & 1.00 & 1.00 \\
\hline $25-39$ & $2.08(1.25 \text { to } 3.48)^{*}$ & 0.97 (0.61 to 1.53$)$ & $1.40(0.61$ to 3.24$)$ \\
\hline $40-54$ & $2.50(1.44 \text { to } 4.32)^{*}$ & 0.93 (0.56 to 1.54$)$ & 2.36 (0.96 to 5.80$)$ \\
\hline $55+$ & $2.32(1.31 \text { to } 4.11)^{*}$ & $1.10(0.65$ to 1.87$)$ & $3.64(1.48 \text { to } 8.96)^{*}$ \\
\hline \multicolumn{4}{|l|}{ Gender } \\
\hline Male & 1.00 & 1.00 & 1.00 \\
\hline Female & 0.65 (0.41 to 1.03$)$ & $0.61(0.38 \text { to } 0.98)^{\star}$ & $0.49(0.26 \text { to } 0.90)^{*}$ \\
\hline \multicolumn{4}{|l|}{ Marital status } \\
\hline Married & 1.00 & 1.00 & 1.00 \\
\hline Never married & 0.90 (0.67 to 1.21$)$ & $0.87(0.65$ to 1.17$)$ & 0.82 (0.51 to 1.32$)$ \\
\hline Others & 1.07 (0.72 to 1.58$)$ & 1.19 (0.81 to 1.75$)$ & 1.27 (0.82 to 1.97$)$ \\
\hline \multicolumn{4}{|l|}{ Educational attainment } \\
\hline Middle school or less & 1.00 & 1.00 & 1.00 \\
\hline High school & $0.72(0.56 \text { to } 0.94)^{*}$ & 0.88 (0.67 to 1.15$)$ & $0.62(0.45 \text { to } 0.85)^{*}$ \\
\hline College or more & 0.83 (0.62 to 1.10$)$ & 0.84 (0.62 to 1.13$)$ & $0.53(0.37 \text { to } 0.76)^{*}$ \\
\hline \multicolumn{4}{|l|}{ Household equivalent income $†$} \\
\hline Low & 1.00 & 1.00 & 1.00 \\
\hline Middle & 1.09 (0.86 to 1.38$)$ & 0.92 (0.73 to 1.17$)$ & 1.22 (0.90 to 1.65$)$ \\
\hline High & 1.11 (0.88 to 1.39$)$ & 0.93 (0.74 to 1.18$)$ & 0.89 (0.65 to 1.23$)$ \\
\hline \multicolumn{4}{|l|}{ Cigarettes per day } \\
\hline $1-10$ & 1.00 & 1.00 & 1.00 \\
\hline $11-20$ & $0.76(0.63 \text { to } 0.92)^{*}$ & $0.77(0.63 \text { to } 0.95)^{*}$ & $0.92(0.70$ to 1.20$)$ \\
\hline $21+$ & $0.64(0.48 \text { to } 0.85)^{*}$ & $0.82(0.60$ to 1.11$)$ & $1.11(0.74$ to 1.66$)$ \\
\hline \multicolumn{4}{|l|}{ Total home smoking ban } \\
\hline No & 1.00 & 1.00 & 1.00 \\
\hline Yes & 1.15 (0.96 to 1.37$)$ & $1.39(1.16 \text { to } 1.67)^{*}$ & $1.63(1.28 \text { to } 2.09)^{\star}$ \\
\hline \multicolumn{4}{|l|}{ Smoking restriction in automobile } \\
\hline No & 1.00 & 1.00 & 1.00 \\
\hline Yes & $1.66(1.36 \text { to } 2.03)^{\star}$ & $1.66(1.35 \text { to } 2.04)^{*}$ & $2.10(1.57 \text { to } 2.81)^{\star}$ \\
\hline \multicolumn{4}{|l|}{ Time-in-sample } \\
\hline Once & 1.00 & 1.00 & 1.00 \\
\hline Twice & $1.42(1.15 \text { to } 1.75)^{\star}$ & $1.44(1.17 \text { to } 1.77)^{*}$ & $1.38(1.05 \text { to } 1.82)^{*}$ \\
\hline Thrice & 0.92 (0.63 to 1.36$)$ & 1.35 (0.92 to 1.98$)$ & $1.76(1.10 \text { to } 2.80)^{*}$ \\
\hline \multicolumn{4}{|l|}{ Survey year } \\
\hline 2008 & 1.00 & 1.00 & 1.00 \\
\hline
\end{tabular}




\begin{tabular}{|c|c|c|c|}
\hline & $\begin{array}{l}\text { Workplace } \\
(n=3475)\end{array}$ & $\begin{array}{l}\text { Restaurants or cafes } \\
(n=3530)\end{array}$ & $\begin{array}{l}\text { Drinking } \\
\text { establishments } \\
(n=3494)\end{array}$ \\
\hline 2005 & $0.57(0.45 \text { to } 0.72)^{*}$ & $0.54(0.42 \text { to } 0.70)^{*}$ & $0.54(0.38 \text { to } 0.78)^{\star}$ \\
\hline 2010 & 1.04 (0.84 to 1.28$)$ & 0.92 (0.75 to 1.13$)$ & $0.93(0.71$ to 1.21$)$ \\
\hline
\end{tabular}

${ }^{*} \mathrm{P}$ value $<0.05$ from GEE regression.

†Low: <30 000000 won; middle: 30000 000-44 999000 won; high: $\geq 45000000$ won.

GEE, generalised estimating equation.

indoor and outdoor areas of restaurants/cafes/drinking establishments). This result was contrary to that of a US study. ${ }^{28}$ The anti-smoking campaigns may not have had a positive effect on smokers' support for total smoking bans, because total smoking bans in restaurants or cafes were not introduced until 2012. Korean smokers were allowed to smoke in DSAs in public places during the study period. So, smokers may think that a total smoking ban is too strict, although they know the adverse health effect of SHS through anti-smoking advertising. ${ }^{12} 29$

In addition, in the ITC Korea survey, respondents were asked if they had noticed anti-smoking advertising or information about the dangers of smoking or that encouraged quitting. It is possible that advertising concerning smoking cessation may have less influence on smokers' attitudes towards smoking bans in public places, compared with advertisements about harms of SHS. More research is required regarding the effects of anti-smoking campaigns on Korean smokers' support for total smoking bans.

Previous studies show that implementing smoke-free policies results in changed attitudes towards smoking bans in public places. ${ }^{30-32}$ Kelly et al. found that the implementation of a smoke-free law reinforced the denormalisation of smoking. ${ }^{18}$ Korean smokers' preference for partial smoking bans (ie., DSAs allowed) may, in part, be attributable to the fact that Korean law permitted DSAs until 2012. Similarly, low support for total smoking bans in restaurants/bars was reported in China, where there was no national smoking restrictions in these venues. ${ }^{33}$ We also found that support for total smoking bans in drinking establishments, where smoking was not regulated, was lower than those in the indoor areas of restaurants/cafes or outdoor public places, such as bus stops.

A commonly cited concern is that a total ban on smoking in public places will lead to an increase in smoking in private places such as homes or vehicles. In fact, previous studies have shown that $100 \%$ smoke-free bans are associated with stronger personal bans in private homes. ${ }^{32}{ }^{34-37}$ We found that the proportion of smokers who reported rules against smoking in their homes or vehicles increased between 2005 and 2010; however, despite this relative increase, in 2010, around half of Korean smokers reported smoking in their homes.

Many Koreans, including children, are exposed to SHS; specifically, $17.8 \%$ of Korean men and women are exposed to SHS in the indoor areas of workplaces, and $21.1 \%$ are exposed in public indoor areas. ${ }^{15}$ Total smoking bans are more effective than partial bans (which allow DSAs) in reducing SHS exposure. ${ }^{181138-40}$ In fact, Fernández et al. found that partial bans in hospitality venues were ineffective in reducing SHS exposure. ${ }^{38}$

Support for bans in public places increased in Korea between 2005 and 2008, although overall support for total smoking bans in Korea was lower than in ITC countries such as Australia and Thailand. ${ }^{1031}$ Studies in other countries have shown that support for smoking bans increased after the implementation of smoke-free laws. ${ }^{69}{ }^{41}$ More smoke-free regulations have been implemented since 2005, and smokers may come to accept that smoking in public places is undesirable or socially unacceptable. Smokers' attitudes towards smoking bans should be carefully monitored with the expansion of smoke-free policies. As Korea's national smoke-free restaurants policy was introduced in December 2012, additional studies are required to examine the impact of this law on smokers' attitudes and compliance.

Using longitudinal study design analysis, this study showed that Korean smokers' support towards smoking bans in public places increased during the period of the introduction of smoke-free policies (2005-2010). The findings of this study should be considered in light of its limitations. First, the ITC Korea Survey relies on self-reported measures; thus, recall bias and social desirability may have influenced respondents' answers. Second, although we analysed the data using weights and adjusted for time-in-sample, the high attrition rate between waves was another limitation of our study. Third, the study population consisted of smokers only, so the results may not be generalisable to non-smokers or to the general population, particularly since non-smokers may be more likely to support total smoking bans. ${ }^{42}{ }^{43}$ Finally, the majority of respondents were men, since smoking prevalence among Korean women was low. Therefore, further research incorporating more female smokers is needed to assess their knowledge, attitudes and behaviours in more detail.

\section{CONCLUSION}

Although the proportion of smokers who support total smoking bans is lower in Korea than it is in Western countries, such as Australia, France and Ireland, this paper 
Table 4 Odds ratio $(95 \% \mathrm{Cl})$ of support for a total smoking ban in outdoor areas of public places, ITC Korea Survey Wave 2 (2008) and Wave 3 (2010)

\begin{tabular}{ll}
$\begin{array}{l}\text { Restaurants or cafes } \\
(n=2628)\end{array}$ & $\begin{array}{l}\text { Drinking establishments } \\
(n=2615)\end{array}$ \\
\hline
\end{tabular}

Notice anti-smoking advertising or information

No

1.00

1.00

Yes

0.82 (0.56 to 1.19$)$

0.90 (0.57 to 1.42 )

Smoke is dangerous to non-smokers

Do not agree/neither agree nor disagree

1.00

1.00

Strongly agree or agree

1.56 (0.87 to 2.80$)$

1.00 (0.51 to 1.94$)$

Age (years)

18-24

1.00

1.00

25-39

1.55 (0.57 to 4.22$)$

40-54

2.02 (0.68 to 6.03$)$

1.31 ( 0.32 to 5.41$)$

$55+$

2.08 (0.70 to 6.20$)$

$2.30(0.51$ to 10.39$)$

Gender

Male

1.00

3.26 (0.70 to 15.14$)$

Female

0.68 (0.28 to 1.67$)$

1.00

Marital status

Married

1.00

0.79 (0.30 to 2.03$)$

Never married

1.28 (0.70 to 2.37 )

1.00

Others

1.97 (1.12 to 3.45$)^{\star}$

1.04 (0.46 to 2.35)

Educational attainment

Middle school or less

1.00

1.63 (0.92 to 2.90$)$

High school

0.93 (0.58 to 1.51$)$

1.00

College or more

0.65 (0.36 to 1.18$)$

0.76 (0.43 to 1.35$)$

Household equivalent income $†$

\begin{tabular}{|c|c|c|}
\hline Low & 1.00 & 1.00 \\
\hline Middle & 1.07 (0.67 to 1.70$)$ & $0.92(0.51$ to 1.67$)$ \\
\hline High & $1.11(0.69$ to 1.80$)$ & 1.29 (0.75 to 2.22$)$ \\
\hline $1-10$ & 1.00 & 1.00 \\
\hline $11-20$ & 0.81 (0.55 to 1.17$)$ & 0.91 (0.58 to 1.44$)$ \\
\hline No & 1.00 & 1.00 \\
\hline Yes & 1.29 (0.89 to 1.89$)$ & $1.29(0.83$ to 2.00$)$ \\
\hline \multicolumn{3}{|c|}{ Smoking restriction in automobile } \\
\hline No & 1.00 & 1.00 \\
\hline Twice & $0.79(0.54$ to 1.16$)$ & 0.91 (0.59 to 1.40$)$ \\
\hline Thrice & $0.39(0.20 \text { to } 0.77)^{\star}$ & 0.71 (0.34 to 1.50$)$ \\
\hline \multicolumn{3}{|c|}{ Survey year } \\
\hline 2008 & 1.00 & 1.00 \\
\hline 2010 & $3.46(2.33 \text { to } 5.11)^{*}$ & 1.32 (0.87 to 2.00$)$ \\
\hline
\end{tabular}

${ }^{*} P$ value $<0.05$

†Low: $<30000000$ won; middle: 30000 000-44 999000 won; high: $\geq 45000000$ won. 
found a significant increase in the support of Korean smokers for smoking bans in public places between 2005 and 2008. This shows that smokers' attitudes towards smoking bans have changed in response to the implementation of smoke-free policies in Korea, a country that has a high smoking prevalence.

\section{Author affiliations}

${ }^{1}$ Center for Food and Drug Policy Research, Korea Institute for Health and Social Affairs, Sejong, Korea (the Republic of)

${ }^{2}$ Department of Public Health Science, Seoul National University Graduate School of Public Health, Seoul, Korea (the Republic of)

${ }^{3}$ Center for Cancer Prevention and Detection, National Cancer Center, Goyangsi, Korea (the Republic of)

${ }^{4}$ Total Healthcare Center, Kangbuk Samsung Hospital, Seoul, Korea (the Republic of) ${ }^{5}$ Department of Psychology, University of Waterloo, Waterloo, Ontario, Canada ${ }^{6}$ School of Public Health and Health Systems, University of Waterloo, Waterloo, Ontario, Canada

${ }^{7}$ Ontario Institute for Cancer Research, Toronto, Ontario, Canada

Contributors EP and SIC conceptualised the paper, performed analyses and wrote the manuscript. HGS, YK and H-SJ lead the ITC Korea Survey and managed the collection of data. PD, JO, ACKQ and GTF contributed in the revisions of the manuscript.

Funding The ITC Korea Project was supported by grants from the US National Cancer Institute (R01 CA125116), the Roswell Park Transdisciplinary Tobacco Use Research Center (P50 CA111236) and the Korean Ministry of Health and Welfare and Korean National Cancer Center (0731040-1). Additional support was provided to GTF from a Senior Investigator Award from the Ontario Institute for Cancer Research and a Prevention Scientist Award from the Canadian Cancer Society Research Institute. Additional support in preparing this paper was provided to University of Waterloo by the Canadian Institutes of Health Research (FDN-148477).

Disclaimer GTF has served as an expert witness on behalf of governments in litigation involving the tobacco industry.

Competing interests None declared.

Patient consent for publication Not required.

Ethics approval The study was approved by the institutional review board of the National Cancer Center, Korea, and the Office of Research Ethics of the University of Waterloo, Canada

Provenance and peer review Not commissioned; externally peer reviewed.

Data sharing statement № additional data are available.

Open access This is an open access article distributed in accordance with the Creative Commons Attribution Non Commercial (CC BY-NC 4.0) license, which permits others to distribute, remix, adapt, build upon this work non-commercially, and license their derivative works on different terms, provided the original work is properly cited, appropriate credit is given, any changes made indicated, and the use is non-commercial. See: http://creativecommons.org/licenses/by-nc/4.0/.

\section{REFERENCES}

1. World Health Organization. Protection from exposure to second-hand tobacco smoke. Policy recommendations. Geneva: World Health Organization, 2007.

2. Davey Smith G, Smith GD. Effect of passive smoking on health. BMJ 2003;326:1048-9.

3. Longo DR, Johnson JC, Kruse RL, et al. A prospective investigation of the impact of smoking bans on tobacco cessation and relapse. Tob Control 2001;10:267-72.

4. Myung SK, Seo HG, Cheong YS, et al. Association of sociodemographic factors, smoking-related beliefs, and smoking restrictions with intention to quit smoking in Korean adults: findings from the ITC Korea Survey. J Epidemiol 2012;22:21-7.

5. Hyland A, Barnoya J, Corral JE. Smoke-free air policies: past, present and future. Tob Control 2012;21:154-61.

6. Cooper J, Borland $\mathrm{R}$, Yong $\mathrm{HH}$, et al. Compliance and support for bans on smoking in licensed venues in Australia: findings from the
International Tobacco Control Four-Country Survey. Aust N Z J Public Health 2010;34:379-85.

7. McKee SA, Higbee C, O'Malley S, et al. Longitudinal evaluation of smoke-free Scotland on pub and home drinking behavior: findings from the International Tobacco Control Policy Evaluation Project. Nicotine Tob Res 2009;11:619-26.

8. Naiman AB, Glazier RH, Moineddin R. Is there an impact of public smoking bans on self-reported smoking status and exposure to secondhand smoke? BMC Public Health 2011;11:1-9.

9. Thomson G, Wilson N, Edwards R. At the frontier of tobacco control: a brief review of public attitudes toward smoke-free outdoor places. Nicotine Tob Res 2009;11:584-90.

10. Yong HH, Foong K, Borland R, et al. Support for and reported compliance among smokers with smoke-free policies in airconditioned hospitality venues in Malaysia and Thailand: findings from the International Tobacco Control Southeast Asia Survey. Asia Pac J Public Health 2010;22:98-109.

11. Nagelhout GE, Mons U, Allwright S, et al. Prevalence and predictors of smoking in "smoke-free" bars. Findings from the International Tobacco Control (ITC) Europe Surveys. Soc Sci Med 2011;72:1643-51.

12. Park EY, Lim MK, Yang W, et al. Policy effects of secondhand smoke exposure in public places in the Republic of Korea: evidence $\mathrm{PM}_{25}$ levels and air nicotine concentrations. Asian Pac J Cancer Prev 2013;14:7725-30.

13. Seo K-H, Shin C-S. Effects of the smoke-free apartment project in Seoul. Health and social science 2012;32:71-92.

14. Lee HA, Park H, Kim H, et al. The effect of community-level smokefree ordinances on smoking rates in men based on Community Health Surveys. Epidemiol Health 2014;36:e2014037.

15. Ministry of Health and Welfare of Korea, Korea Centers for Disease Control and Prevention. 2016 The seventh Korea National Health and Nutrition Examination Survey. Sejong, 2017.

16. Kim SS, Son H, Nam KA. The sociocultural context of korean american men's smoking behavior. West J Nurs Res 2005;27:604-23.

17. Brown A, Moodie C, Hastings G. A longitudinal study of policy effect (smoke-free legislation) on smoking norms: ITC Scotland/United Kingdom. Nicotine Tob Res 2009;11:924-32.

18. Kelly BC, Vuolo M, Frizzell LC, et al. Denormalization, smoke-free air policy, and tobacco use among young adults. Soc Sci Med 2018;211:70-7.

19. Kelly BC. Smoke-free air policy: subcultural shifts and secondary health effects among club-going young adults. Sociol Health IIIn 2009;31:569-82.

20. Fong GT, Cummings KM, Borland R, et al. The conceptual framework of the International Tobacco Control (ITC) Policy Evaluation Project. Tob Control 2006;15:iii3-11.

21. Seo HG, Kim Y, Xu SS, et al. Tobacco control policies in the Republic of Korea and the methods of the ITC Korea Surveys. J Korean Soc Res Nicotine Tob 2018;9:S1-10.

22. ITC Project. ITC Korea National Report. Findings from the Wave 1 to 3 Surveys (2005-2010). Waterloo, Ontario, Canada: University of Waterloo, National Cancer Center and Korean Association on Smoking or Health, Republic of Korea, 2012.

23. ITC Project. ITC Korea Wave 2 (2008) Technical Report. Waterloo, Ontario, Canada, Republic of Korea: University of Waterloo, National Cancer Center and Korean Association on Smoking or Health, 2009.

24. ITC Project. ITC Korea Wave 3 (2010) Technical Report. Waterloo, Ontario, Canada, Republic of Korea: University of Waterloo, National Cancer Center and Korean Association on Smoking or Health, 2011.

25. Kwak SM, Myung SK, Kim Y, et al. Analysis of smoking-related characteristics over time in korean adult smokers: findings from the International Tobacco Control (ITC) Korea Survey. Korean J Fam Pract 2011:1:192-203.

26. ITC Project. ITC Korea Wave 1(2005) Technical Report. Waterloo, Ontario, Canada, Republic of Korea: University of Waterloo, National Cancer Center and Korean Association on Smoking or Health, 2008.

27. Park EJ, Koh HK, Kwon JW, et al. Secular trends in adult male smoking from 1992 to 2006 in South Korea: age-specific changes with evolving tobacco-control policies. Public Health 2009;123:657-64.

28. Niederdeppe J, Kellogg M, Skurka C, et al. Market-level exposure to state antismoking media campaigns and public support for tobacco control policy in the United States, 2001-2002. Tob Control 2018;27:177-84.

29. Lee H, Paek H-J. Impact of norm perceptions and guilt on audience response to anti-smoking norm PSAs: The case of Korean male smokers. Health Educ J 2013;72:503-11.

30. Borland R, Yong HH, Siahpush M, et al. Support for and reported compliance with smoke-free restaurants and bars by smokers in four 
countries: findings from the International Tobacco Control (ITC) Four Country Survey. Tob Control 2006;15:iii34-iii41.

31. Hyland A, Higbee C, Borland R, et al. Attitudes and beliefs about secondhand smoke and smoke-free policies in four countries: findings from the International Tobacco Control Four Country Survey. Nicotine Tob Res 2009;11:642-9.

32. Mons U, Nagelhout GE, Allwright S, et al. Impact of national smoke-free legislation on home smoking bans: findings from the International Tobacco Control Policy Evaluation Project Europe Surveys. Tob Control 2013;22:e2-e9.

33. Li Q, Hyland A, O'Connor R, et al. Support for smoke-free policies among smokers and non-smokers in six cities in China: ITC China Survey. Tob Control 2010;19(Suppl 2):i40-6.

34. Borland R, Yong HH, Cummings KM, et al. Determinants and consequences of smoke-free homes: findings from the International Tobacco Control (ITC) Four Country Survey. Tob Control 2006;15:iii42-50.

35. Fong GT, Hyland A, Borland R, et al. Reductions in tobacco smoke pollution and increases in support for smoke-free public places following the implementation of comprehensive smoke-free workplace legislation in the Republic of Ireland: findings from the ITC Ireland/UK Survey. Tob Control 2006;15:iii51-8.

36. Hitchman SC, Fong GT, Borland R, et al. Predictors of smoking in cars with nonsmokers: findings from the 2007 Wave of the
International Tobacco Control Four Country Survey. Nicotine Tob Res 2010:12:374-80.

37. Hitchman SC, Guignard R, Nagelhout GE, et al. Predictors of car smoking rules among smokers in France, Germany and the Netherlands. Eur J Public Health 2012;22(suppl 1):17-22.

38. Fernández E, Fu M, Pascual JA, et al. Impact of the Spanish smoking law on exposure to second-hand smoke and respiratory health in hospitality workers: a cohort study. PLoS One 2009;4:e4244.

39. Heloma A, Jaakkola MS. Four-year follow-up of smoke exposure, attitudes and smoking behaviour following enactment of Finland's national smoke-free work-place law. Addiction 2003;98:1111-7.

40. Hyland A, Hassan LM, Higbee C, et al. The impact of smokefree legislation in Scotland: results from the Scottish ITC: Scotland/UK longitudinal surveys. Eur J Public Health 2009;19:198-205.

41. Brooks DR, Mucci LA. Support for smoke-free restaurants among Massachusetts adults, 1992-1999. Am J Public Health 2001;91:300-3.

42. Lam TH, Janghorbani M, Hedley AJ, et al. Public opinion on smokefree policies in restaurants and predicted effect on patronage in Hong Kong. Tob Control 2002;11:195-200.

43. Li X, Li Q, Dong L, et al. Risk factors associated with smoking behaviour in recreational venues: findings from the International Tobacco Control (ITC) China Survey. Tob Control 2010;19(Suppl 2):i30-9. 